\title{
SÍNTESE DOS ANALGÉSICOS PARACETAMOL E FENACETINA E DO ADOÇANTE DULCINA: UM PROJETO PARA QUÍMICA ORGÂNICA EXPERIMENTAL
}

\author{
Lúcia H. B. Baptistella, Rosana A. Giacomini e Paulo M. Imamura* \\ Instituto de Química, Universidade Estadual de Campinas, CP 6154, 13083-970 Campinas-SP
}

Recebido em 7/2/02; aceito em 12/6/02

\begin{abstract}
SYNTHESIS OF ANALGESICS PARACETAMOL AND PHENACETIN AND THE SWEETENER DULCIN: A PROJECT FOR UNDERGRADUATE ORGANIC CHEMISTRY LABORATORY. A synthesis of artificial sweetener dulcin starting from nitrobenzene was elaborated for undergraduate organic laboratory course. Paracetamol and phenacetin, both physiologically active analgesic compounds, were also prepared as intermediates. Besides a large scope of discussion subjects related with organic synthesis, interesting lectures about analgesics and sweeteners may also be performed in this project. The advantage of this project is the adaptability according to the conditions offered by the course, i.e., convenience and/or availability of time and reagents.
\end{abstract}

Keywords: aromatic compounds; analgesics paracetamol and phenacetin; sweetener dulcin.

\section{INTRODUÇÃO}

Considerando a tendência generalizada de redução de cargas horárias nos cursos de graduação em química, torna-se imprescindível, no que se refere a disciplinas experimentais, um excelente planejamento de experimentos que sejam adequados aos objetivos de ensino $^{1}$. Quando se trata de uma disciplina experimental no período noturno, a limitação de tempo se torna ainda mais crítica e, neste sentido, há a necessidade de práticas versáteis, que apresentem algumas possibilidades para interrupções sem perda da qualidade dos resultados finais. Assim, visando a elaboração de experimentos para uma disciplina experimental avançada de química orgânica no período noturno, com uma carga horária semanal de $6 \mathrm{~h}(4+2 \mathrm{~h})$, pensou-se em projetos de síntese que envolvessem seqüências de 4 a 6 etapas com as seguintes características: compatibilidade com o tempo disponível, produtos de fácil purificação e caracterização, possibilidade de manipulação em escala semi-micro ou micro e, principalmente, experimentos que permitissem aos alunos a sedimentação de conceitos básicos, com exemplos envolvendo aspectos de suas vidas cotidianas. Foi publicado recentemente um experimento para laboratório de ensino envolvendo a preparação da dulcina ${ }^{2}$, um adoçante sintético, a partir do analgésico acetaminofeno, conhecido também como paracetamol. No entanto, a sequiência mostrada (parte experimental disponível apenas por assinatura da revista "online", a qual, segundo informações, não é feita por nenhuma biblioteca do Brasil) não funcionou como descrito, e os resultados não se reproduziram. Assim, por todas as razões descritas acima e pelo interesse que sínteses de substâncias com atividades biológicas, como é o caso de analgésicos ou adoçantes, normalmente desperta nos alunos, decidimos investigar melhor essa preparação e adaptá-la aos nossos laboratórios. Os resultados são discutidos a seguir.

\section{RESULTADOS E DISCUSSÃO}

Historicamente, a dulcina foi o segundo adoçante sintético a ser lançado no mercado, há mais de cem anos ${ }^{3}$, atrás apenas da sacarina. Apesar de seu excelente poder adoçante, testes in vivo com mamíferos, inclusive o homem, evidenciaram toxicidade, levando-a a ser

*e-mail: imam@iqm.unicamp.br retirada do comércio após quase 60 anos de uso ${ }^{3}$. Mesmo não sendo mais comercializada, sua preparação a partir de substratos facilmente acessíveis, utilizando uma rota sintética que também envolva intermediários com outros tipos de atividades sobre o organismo humano, desperta muito interesse.

A sequiência sintética está indicada no Esquema 1.

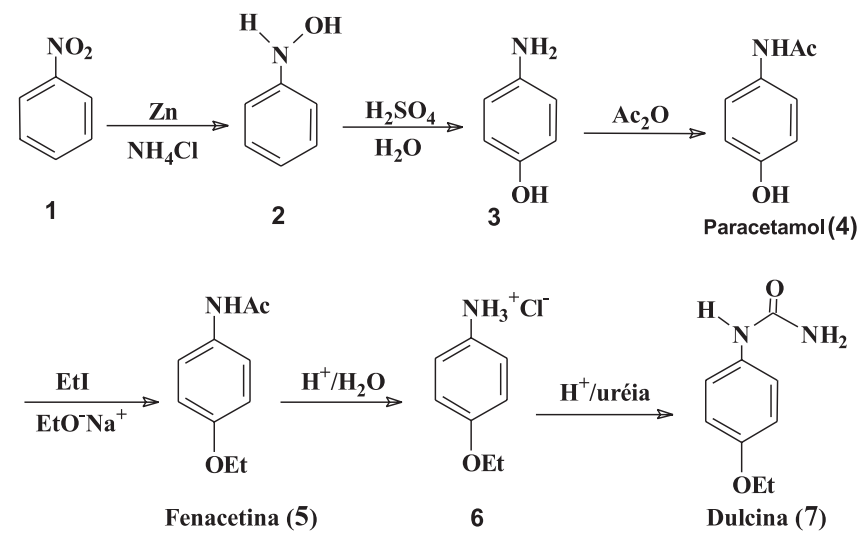

Esquema 1. Síntese do paracetamol (4), da fenacetina (5) e da dulcina (7) a partir do nitrobenzeno (1)

Este projeto pode ser iniciado pela reação de nitração do benzeno ${ }^{4}$, dependendo da disponibilidade de tempo e das condições do laboratório, como capela com um bom sistema de exaustão. Recomendamos, neste caso, uma reação em escala micro ou semi-micro com ácido nítrico gerado in situ ${ }^{5}$. Em nosso projeto, decidimos iniciar pelo nitrobenzeno (1). Este foi submetido a uma reação de redução com zinco metálico na presença de cloreto de amônio, um procedimento clássico ${ }^{6}$ que leva à formação do sólido instável N-fenilhidroxilamina (2), imediatamente tratado com uma solução de ácido sulfúrico para obtenção do $p$-aminofenol (3). Algumas modificações do método, a começar pela diminuição da escala para 1/5 do indica$\mathrm{do}^{6}$, permitiram que 3 fosse preparado em bom rendimento num período de $4 \mathrm{~h}$. Assim, um pré-aquecimento da solução contendo 1 antes da introdução do zinco em pó, de modo a manter a temperatura de reação entre a $60-65^{\circ} \mathrm{C}$, foi fundamental para que bons resultados 
na obtenção de $\mathbf{2}$ fossem conseguidos. Este produto, bruto, foi utilizado imediatamente para a etapa de rearranjo em meio ácido. Ao final, a extração do $p$-aminofenol (3) da solução aquosa foi conduzida com acetato de etila ao invés de éter etílico, sugerido no procedimento original ${ }^{6}$. Este solvente, muito mais adequado para uso em laboratórios de ensino ${ }^{7}$, também se mostrou mais eficiente para a extração do produto. $\mathrm{O}$ p-aminofenol (3), obtido em $62 \%$ de rendimento, foi caracterizado por p.f. e análise do espectro no IV, ambos feitos em uma aula de $2 \mathrm{~h}$.

A acetilação de $\mathbf{3}$ foi efetuada sem maiores dificuldades, conforme procedimento descrito na literatura ${ }^{8}$, isolando-se o paracetamol (4), conhecido também como acetaminofeno, em rendimentos de $65 \%$. Para efeito de comparação, os alunos efetuaram, nesta mesma aula, um procedimento para extração do analgésico 4 a partir de comprimidos comerciais de Tylenol ${ }^{\circledR}$. Com um rendimento médio de $65 \%$ nas extrações, foi possível a caracterização do produto por p.f. e dados espectroscópicos no IV.

O paracetamol (4) foi, em seguida, submetido à reação de Williamson $^{8}$, fornecendo a fenacetina (5) em $60 \%$ de rendimento. A utilização de sódio metálico para gerar a solução de etóxido de sódio em etanol nesta etapa permite um aprendizado bastante amplo de reações em meio anidro, e leva ao produto desejado em um bom grau de pureza para a continuação da síntese.

Para a preparação da dulcina (7) testamos alguns métodos inclusive o que foi descrito recentemente no Journal of Chemical Education $^{2}$, no entanto os melhores resultados foram conseguidos efetuando-se pequenas modificações em um procedimento clássico ${ }^{9-11}$. Desse modo, a fenacetina (5) foi submetida a uma reação de hidrólise ácida ${ }^{11}$, isolando-se o cloridrato da fenetidina (6) em $75 \%$ de rendimento, caracterizado por seus dados espectroscópicos no IV. Finalmente, o cloridrato 6 foi tratado com uréia em uma solução ácida de $\mathrm{HCl}$ :ácido acético ${ }^{9,10}$, fornecendo a dulcina (7) em rendimento de $83 \%$. Apesar de ser possível evidenciar o enorme poder adoçante do produto por um teste gustativo (sem ingestão), este não é recomendado e o sucesso da síntese pode ser comprovado por métodos normais para caracterização, como ponto de fusão e espectroscopia na região do infravermelho.

\section{CONCLUSÃO}

Em resumo, o presente projeto cumpre com os objetivos apresentados. Em 5 semanas foi possível a realização, com sucesso, das 6 etapas descritas, permitindo tanto discussões acerca dos vários aspectos químicos inerentes a trabalhos de síntese orgânica, como reatividade de grupos funcionais, técnicas de laboratório, métodos cromatográficos, processos para purificação e caracterização física e espectroscópica dos produtos, quanto uma série de leituras e discussões que despertaram interesse, como aquelas associadas a propriedades e fatos históricos dos adoçantes não calóricos ${ }^{3,12}$ e à atividade analgésica dos intermediários ${ }^{13}$. Adicionalmente, a facilidade de preparação ou mesmo de compra dos intermediários implica numa enorme flexibilização do projeto, com o número de etapas podendo ser ajustado de acordo com a disponibilidade de tempo da disciplina ou de reagentes no laboratório.

\section{PARTE EXPERIMENTAL}

Os rendimentos citados nas várias etapas são os rendimentos médios da turma.

\section{Síntese da N-fenil-hidroxilamina (2) e do $p$-aminofenol $(3)^{6}$}

Em um béquer de $500 \mathrm{~mL}$ foram colocados 5,0 g (93,5 mmol) de
$\mathrm{NH}_{4} \mathrm{Cl}, 160,0 \mathrm{~mL}$ de água e $10,0 \mathrm{~g}(8,3 \mathrm{~mL}-81,2 \mathrm{mmol}) \mathrm{de}$ nitrobenzeno recém destilado. A solução, sob vigorosa agitação magnética, foi aquecida a $60{ }^{\circ} \mathrm{C}$ numa placa de aquecimento. Após desligar o aquecimento foram adicionados 12,0 $\mathrm{g}$ (165,2 $\mathrm{mmol})$ de zinco em pó ( $90 \%$ de pureza), em pequenas porções, de forma a manter a temperatura da solução em torno de $60-65^{\circ} \mathrm{C}$ ( 10 min). A solução foi mantida sob agitação vigorosa por mais 15 min e em seguida, ainda quente, filtrada num funil de Büchner para remover o óxido de zinco formado. O sólido foi lavado com $20,0 \mathrm{~mL}$ de água quente e em seguida o filtrado foi transferido para um erlenmayer, saturado com cloreto de sódio $(\sim 40,0 \mathrm{~g})$ e resfriado num banho de gelo. Os cristais amarelo claros formados foram filtrados num funil de Büchner para fornecer $5,93 \mathrm{~g}$ da $\mathrm{N}$-fenil-hidroxilamina (2), p.f. $78-80{ }^{\circ} \mathrm{C}$. Este produto foi imediatamente convertido a $p$-aminofenol (3).

Em um béquer de $1000 \mathrm{~mL}$ contendo 74,0 g de gelo picado, num banho de gelo, foram adicionados lentamente $24,5 \mathrm{~mL}$ de ácido sulfúrico concentrado e em seguida $5,93 \mathrm{~g}$ da $\mathrm{N}$-fenil-hidroxilamina (2). A solução foi diluída com $490 \mathrm{~mL}$ de água e aquecida até a ebulição. Após 15 min a solução foi resfriada e neutralizada com bicarbonato de sódio, saturada com cloreto de sódio e extraída com acetato de etila ( 3 x 100,0 mL). A solução orgânica foi seca com sulfato de sódio anidro, filtrada e o solvente removido num evaporador rotativo. Foram obtidos 3,67 g (62\%) de $p$-aminofenol (3) como um sólido de cor vinho, p.f. $184-186^{\circ} \mathrm{C}$; IV $(\mathrm{KBr}) \vee\left(\mathrm{cm}^{-1}\right)$ : 3345, 3290, 2685, 2580, 1612, 1510, 1410, 1237, 1170, 1150, 1090, 970, 705.

\section{Síntese do paracetamol (acetaminofeno, $p$-hidroxiacetanilida) (4) ${ }^{8}$}

Em um erlenmayer de $125 \mathrm{~mL}$ contendo $3,3 \mathrm{~g}(30,2 \mathrm{mmol})$ de $p$ aminofenol e 9,0 $\mathrm{mL}$ de água, foram adicionados 3,6 $\mathrm{mL}$ (32,6 mmol) de anidrido acético, sob agitação contínua. Em seguida, a solução foi aquecida em banho-maria até a dissolução completa do sólido. Após 10 min a solução foi resfriada e colocada num banho de gelo para precipitação do paracetamol (4). Os cristais foram filtrados num funil de Büchner e lavados com água gelada $(\sim 5,0 \mathrm{~mL})$ para fornecer $2,97 \mathrm{~g}(65 \%)$ de produto cristalino de cor levemente rosada, p.f. $167-169^{\circ} \mathrm{C}$; IV $(\mathrm{KBr}) \vee\left(\mathrm{cm}^{-1}\right): 3327,3201,2995,1657,1613,1562$, 1510, 1375, 1244, 1016, 966, 837, 714.

\section{Extração do paracetamol (4) a partir do Tylenol ${ }^{\circledR}$}

Dois comprimidos de Tylenol ${ }^{\circledR}(750 \mathrm{mg} / \mathrm{cada})$ foram triturados em um almofariz e transferidos para um erlenmayer de $125 \mathrm{~mL}$. Foram adicionados 40,0 mL de acetato de etila e a suspensão foi agitada vigorosamente. A solução foi mantida por pelo menos 5 min com agitação ocasional e em seguida filtrada para um balão tarado. O resíduo foi lavado com mais $10,0 \mathrm{~mL}$ de acetato de etila e o solvente foi, em seguida, removido no evaporador rotativo, fornecendo $0,98 \mathrm{~g}(65 \%)$ do paracetamol (4). O produto foi caracterizado através do seu ponto de fusão e espectro no IV.

\section{Síntese da fenacetina $(5)^{8}$}

Em um balão de $100 \mathrm{~mL}$ contendo $10,0 \mathrm{~mL}$ de etanol absoluto e equipado com condensador de refluxo, foram adicionados $0,4 \mathrm{~g}(17,4$ mmol) de sódio e a solução foi agitada até consumo total do metal. Foram adicionados 2,5 g (16,5 mmol) do paracetamol e em seguida $3,8 \mathrm{~g}(2,0 \mathrm{~mL}-24,2 \mathrm{mmol})$ de iodeto de etila, lentamente. A solução foi aquecida por $50 \mathrm{~min}$ mantendo um refluxo suave. Após este período foram adicionados, pelo topo do condensador, 25,0 mL de água e a solução foi aquecida até a dissolução do precipitado formado. Esta foi então resfriada e colocada num banho de gelo para precipitação da fenacetina (5). O produto foi filtrado num funil de Büchner 
para fornecer $1,78 \mathrm{~g}(60 \%)$ de cristais levemente rosados, p.f. 135$137{ }^{\circ} \mathrm{C}$; IV $(\mathrm{KBr}) \vee\left(\mathrm{cm}^{-1}\right): 3450,3286,3132,2981,2927,1658$, 1600, 1558, 1510, 1368, 1263, 1248, 1174, 1047, 937, 837, 780. Caso a fenacetina (5) esteja impura (muito colorida), recomenda-se que se faça recristalização utilizando carvão ativo.

\section{Síntese do cloridrato de $p$-fenetidina (6). Hidrólise da fenacetina ${ }^{11}$}

Em um balão de $25 \mathrm{~mL}$ contendo 1,64 g (9,2 mmol) da fenacetina (5) foram adicionados $8,0 \mathrm{~mL}$ de uma solução $\mathrm{HCl}: \mathrm{H}_{2} \mathrm{O}(1: 1)$. A solução foi aquecida em uma manta de aquecimento até a ebulição e mantida sob refluxo por $40 \mathrm{~min}$. A solução foi resfriada e em seguida colocada num banho de gelo para precipitação do sal cloridrato de $p$-fenetidina (6). O produto foi filtrado num funil de Büchner (não lavar os cristais! - usar a própria $\mathrm{H}_{2} \mathrm{O}$ mãe que está no kitassato para transferir eventual produto que tenha ficado na parede do balão), e os cristais foram guardados em um dessecador até a aula seguinte. Foram obtidos 1,20 g (75\%) do cloridrato de fenetidina (6); IV $(\mathrm{KBr}) \vee\left(\mathrm{cm}^{-1}\right): 3431,2980,2878,1612,1514,1263,826,806$.

\section{Síntese da dulcina $(7)^{9}$}

Em um balão de $10 \mathrm{~mL}$ foram colocados $1,0 \mathrm{~g}(5,8 \mathrm{mmol}) \mathrm{de}$ cloridrato de $p$-fenetidina (6), 1,4 g (23,3 mmol) de uréia, 2,3 mL de água, $0,1 \mathrm{~mL}$ de uma solução contendo ácido clorídrico e ácido acético (1:1). A solução foi refluxada por 30 min e em seguida o condensador foi removido, deixando em ebulição branda por cerca de 10 min para sua concentração. A solução foi resfriada e em seguida colocada num banho de gelo para precipitação da dulcina (7). Os cristais foram filtrados num funil de Büchner e lavados com mínimo de água gelada para remoção de traços de ácido. Foram obtidos $0,86 \mathrm{~g}(83 \%)$ da dulcina, p.f. $172-174^{\circ} \mathrm{C}$; IV $(\mathrm{KBr}) \vee\left(\mathrm{cm}^{-1}\right): 3438,2978,1657,1600$, 1556, 1512, 1448, 1244, 1170, 1116, 1050, 825.

\section{AGRADECIMENTOS}

A todos os alunos que participaram da síntese da dulcina e que permitiram, com muito entusiasmo, a conclusão do projeto com sucesso.

\section{REFERÊNCIAS E NOTAS}

1. Imamura, P. M.; Baptistella, L. H. B.; Quim. Nova 2000, 23, 270; Ferreira, V. F.; Silva, F. C.; Perrone, C. C.; Quim. Nova 2001, 24, 905.

2. Williams, B. D.; Williams, B., Rodino, L.; J. Chem. Educ. 2000, 77, 357.

3. Goldsmith, R. H.; J. Chem. Educ. 1987, 64, 954. Ver referências complementares: Ellis, J. W.; J. Chem. Educ. 1995, 72, 671; Kinghorn, A. D.; Kennelly E. J.; J. Chem. Educ. 1995, 72, 676; Walters D. E.; J. Chem. Educ. 1995, 72, 680.

4. Furniss, B. S.; Hannaford, A. J.; Smith, P. W. G.; Tatchell, A. R.; Vogel's Textbook of Practical Organic Chemistry, 5th. ed., Longman Scientific \& Technical: New York, 1989, p. 854.

5. Strazzolini, P.; Giumanini, A. G.; Runcio, A.; Tetrahedron Lett. 2001, 42, 1387.

6. Ref. 4, p. 955. A N-fenil-hidroxilamina (2) foi preparada em 1/5 da escala indicada.

7. O éter etílico, além de ser um solvente controlado pela polícia federal, é mais caro que o acetato de etila.

8. Ref. 4, p. 985 .

9. Kurzer, F.; Org. Synth. Coll. 1963, Vol. IV, p. 52.

10. Ref. 4, p. 966

11. Pavia, D. L.; Lampman, G. M.; Kriz, G. S.; Organic Laboratory Techniques. A Contemporary Approach, $2^{\text {nd }}$ ed., Saunders College Publishing: Philadelphia, 1982, p. 321.

12. Ager, D. J.; Pantaleone, D. P.; Henderson, S. A.; Katritzky, A. R.; Prakash, I.; Walters, D. E.; Angew. Chem. Int. Ed. 1998, 37, 1803.

13. Korolkovas, A.; Burckhalter, J. H.; Química Farmacêutica, Ed. Guanabara Koogan S. A.: Rio de Janeiro, 1988. 